\title{
DEVELOPMENT OF AN AUTOMATED AC-DC TRANSFER MEASUREMENT SYSTEM FOR VOLTAGE AND CURRENT AT LOW FREQUENCIES
}

\author{
A. K GOVIL, SAOOD AHMAD, BIJENDRA PAL \& P C KOTHARI \\ LF \& HF Voltage, Current \& RF Power Standards, National Physical Laboratory, \\ New Delhi-12, India
}

\begin{abstract}
National Physical Laboratory India (NPLI) is the premier research \& development center and the National Metrology Institute, which provides traceability in measurements by calibration throughout the country. Low Frequency voltage and current are very important quantities in Electrical Metrology. The standards for LF voltage and current are established by assigning AC-DC transfer difference to Thermal Converters (TCs) worldwide. The range of frequencies of these standards is from $10 \mathrm{~Hz}$ to $1 \mathrm{MHz}$ for the voltage level of $1 \mathrm{~V}$ to $1000 \mathrm{~V}$. This paper presents the automation of method of assigning AC-DC transfer difference to thermal converter (from $10 \mathrm{~Hz}$ to 1 $\mathrm{MHz}$ ) makes measurements faster and more accurate through IEEE-488 interface card and cables. The software for this process has been developed using the VEE Pro application, which is a graphical programming environment optimized for use with the electronic instruments. It also minimizes the human involvement and therefore reduces the chances of errors. Using this software, the measurements have been carried on the $6 \mathrm{~V}$ TC with respect to $4 \mathrm{~V} \mathrm{TC}$ at $4 \mathrm{~V}$ level in the frequency range from $10 \mathrm{~Hz}$ to $1 \mathrm{MHz}$. The result shows that the automation has been done successfully.
\end{abstract}

\section{INTRODUCTION}

The need of automation cannot be ignored in the $\mathrm{AC}-\mathrm{DC}$ transfer measurements, as this procedure is tedious, complicated and requires repetition and regular timing. It reduces the operator skill requirements and substantially reduces measurement time. The software [1] for automating the procedure to assign AC-DC Transfer Difference has been written indigenously on VEE Pro application. The desktop computer has been used as IEEE-488 interface controller, which communicates with the equipments [2]. The software automatically records the data in an excel format. This helps in avoiding the huge strain for the operator to record the readings manually after every minute through out the measurement process. The software performs a lot of scientific calculations on the raw data along with measurement uncertainty calculations and produces the useful and meaningful results.

\section{THEORY}

AC-DC transfer difference of thermal converter under calibration $\left(\delta_{\mathrm{x}}\right)$ is defined by equation (1)

$Q_{a c}$ is an rms ac quantity (voltage or current) and

$$
\delta_{x}=\frac{Q_{a c}-Q_{d c}}{Q_{d c}}
$$

$Q_{d c}$ is a dc quantity which, when reversed, produces the same mean output response as the rms ac quantity.

AC-DC transfer differences are usually expressed in parts per million (ppm). A positive sign signifies that more ac than dc was required for the same output response.

The technique [3] used to measure AC-DC transfer difference of TC is little different from the above equation (1). Here we apply $\mathrm{AC}, \mathrm{DC}(+), \mathrm{DC}(-)$ and again AC signal to both the thermal converters (as shown in Fig. 1) and emf responses of both the TCs are recorded simultaneously. The AC-DC transfer difference assigned to TC under calibration $\left(\delta_{\mathrm{x}}\right)$ is calculated using equation (2)

$$
\delta_{x}=\frac{S_{a c}-S_{d c}}{n_{s} S_{d c}}-\frac{X_{a c}-X_{d c}}{n_{x} X_{d c}}+\delta_{s}
$$

Where,

$S_{a c}$ and $X_{a c}$ are the mean emf outputs of the standard and device under calibration (DUC) respectively when AC is applied.

$S_{d c}$ and $X_{d c}$ are the mean emf outputs of the standard and device under calibration (DUC) respectively when DC is applied.

$\delta_{s}$ is the AC-DC transfer difference of the reference standard.

$n_{s}$ and $n_{x}$ are the exponents of the standard and DUC respectively. 


\section{TECHNIQUE}

Figure 1 shows the setup used for the measurement of AC-DC transfer difference. Rated voltage is applied to warm-up TCs for 15 to 30 minutes.. Firstly, nominal AC voltage signal is applied to both the TCs and response in terms of emf output

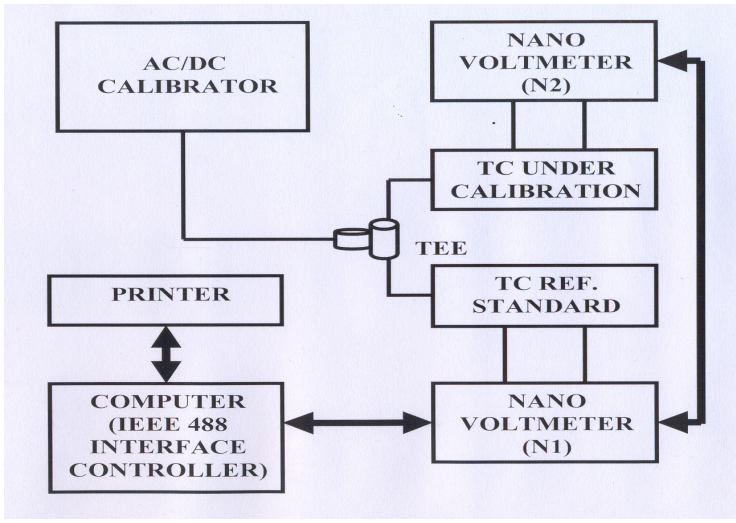

Figure: 1 Block Diagram for the measurement of $A C-D C$ Transfer Difference

measured by the nanovoltmeters is recorded in a excel format. Then $\mathrm{DC}(+), \mathrm{DC}(-)$ \& AC signals are applied and their responses are recorded in the same excel file respectively. This sequence of measurements is used to eliminate the influence of drift in the output of thermal converters. The time gap between successive measurements depends on the time constant of TCs in measurement setup. These measurements are carried out at the environmental conditions of $25 \pm 1{ }^{\circ} \mathrm{C} \& 50 \pm 10 \%$ $\mathrm{RH}$. On completion of a set of ten measurements at a particular frequency, the AC-DC difference and it's uncertainties are calculated by software. The AC-DC difference measurements on other frequencies are repeated as mentioned above.

\section{MEASUREMENT RESULTS}

At $4 \mathrm{~V}$ level a $6 \mathrm{~V}$ thermal converter has been assigned ac-dc transfer difference against $4 \mathrm{~V}$ thermal converter manually as well as using

automation. All the measurement results along with their uncertainties for the manual method and automation method are given in Table 1and Table 2 respectively.

Table 1: Absolute AC-DC Transfer Difference of 6V TC by Manual Method

\begin{tabular}{|r|c|c|}
\hline $\begin{array}{c}\text { Frequency } \\
\text { (Hz) }\end{array}$ & $\begin{array}{c}\text { AC-DC Transfer } \\
\text { Difference (ppm) }\end{array}$ & $\begin{array}{c}\text { Uncertainty } \\
\text { (ppm) }\end{array}$ \\
\hline 10 & 23.8 & \pm 8.4 \\
\hline 40 & 3.6 & \pm 7.0 \\
\hline 1000 & -2.6 & \pm 6.0 \\
\hline 20000 & 4.5 & \pm 6.0 \\
\hline 100000 & 7.7 & \pm 7.0 \\
\hline 1000000 & 43.2 & \pm 24.0 \\
\hline
\end{tabular}

Table 2: Absolute AC-DC Transfer Difference of 6V TC by Automation Method

\begin{tabular}{|r|c|c|}
\hline $\begin{array}{c}\text { Frequency } \\
(\mathbf{H z})\end{array}$ & $\begin{array}{c}\text { AC-DC Transfer } \\
\text { Difference (ppm) }\end{array}$ & $\begin{array}{c}\text { Uncertainty } \\
(\mathbf{p p m})\end{array}$ \\
\hline 10 & -6.8 & \pm 5.1 \\
\hline 40 & 4.4 & \pm 4.5 \\
\hline 1000 & 1.1 & \pm 4.6 \\
\hline 20000 & 4.6 & \pm 5.0 \\
\hline 100000 & 8.5 & \pm 6.6 \\
\hline 1000000 & 64.2 & \pm 27.4 \\
\hline
\end{tabular}

The reported uncertainty is for a coverage factor $\mathrm{k}=2$ which corresponds to a cover probability of approximately $95 \%$ for a normal distribution.

\section{CONCLUSION}

The technique of assigning AC-DC Transfer Difference to thermal converters has been automated successfully using VEE Pro application. The Programming in VEE Pro is faster than basic, $\mathrm{C}$ or $\mathrm{C}++$ programming languages. Therefore, it can be concluded that this automation software is producing technically valid results that are comparable with results from manual method. Thus automation is helpful in saving a lot of time and manpower.

\section{ACKNOWLEDGEMENT}

We are thankful to Dr. Vikram Kumar, Director NPL-India for encouragement and permission to present and publish this work.

\section{REFERENCES}

[1] Programming Manual of VEE-Pro Application Software.

[2] Operating manuals of Calibrator Fluke 5720A and Nanovoltmeter Keithley 182.

[3] Ilya Budovsky, "Algorithm and uncertainty of AC-DC transfer measurements", National Measurement Laboratory CSIRO, Australia. 